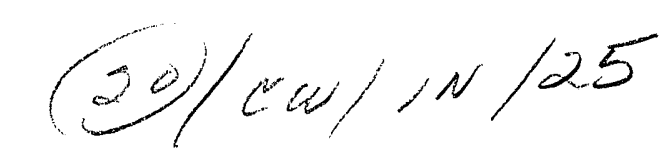

2001 NASA/ASEE SUMMER FACULTY FELLOWSHIP PROGRAM

\author{
JOHN F. KENNEDY SPACE CENTER \\ UNIVERSITY OF CENTRAL FLORIDA
}

\title{
OPERATION, MODELING AND ANALYSIS OF THE REVERSE WATER GAS SHIFT PROCESS
}

\author{
Dr. Jonathan E. Whitlow \\ Associate Professor \\ Department of Chemical Engineering \\ Florida Institute of Technology \\ NASA COLleAgUE: Clyde Parrish
}

\begin{abstract}
The Reverse Water Gas Shift process is a candidate technology for water and oxygen production on Mars under the In-Situ Propellant Production project. This report focuses on the operation and analysis of the Reverse Water Gas Shift (RWGS) process, which has been constructed at Kennedy Space Center. A summary of results from the initial operation of the RWGS process along with an analysis of these results is included in this report. In addition an evaluation of a material balance model developed from the work performed previously under the summer program is included along with recommendations for further experimental work.
\end{abstract}




\section{INTRODUCTION}

The human exploration of Mars will require the utilization of resources present in the Martian environment in order to minimize the payload mass imported from Earth. Reverse Water Gas Shift (RWGS), which reacts carbon dioxide and hydrogen to form water and carbon monoxide, when coupled with water electrolysis is a candidate technology for oxygen production on Mars. The use of the RWGS process for In-Situ Propellant Production, (ISPP) was originally studied by Pioneer Astronautics, who determined the RWGS process to be a viable candidate for oxygen production. ${ }^{[1-2]}$

An RWGS prototype system has been constructed and modified at Kennedy Space Center (KSC) over the past 18 months. While some experimental runs were made on the RWGS system at the end of the year 2000, it was not until July 2001 that successful operation of the process was made with no system leaks. Although the operating time has been limited, several conclusions on the RWGS operation have been made and problem areas identified as discussed in this report. An overview of the process components for RWGS is given below followed by a discussion of the results obtained from operation of the system. An evaluation of the validity of a material balance simulation model for the RWGS process developed under this research program in $1999^{[3]}$ is then presented and followed by a recommendation for further experimental modifications and development.

\section{AN OVERVIEW OF THE REVERSE WATER GAS SHIFT PROCESS}

RWGS uses carbon dioxide and hydrogen as reactants to produce oxygen and carbon monoxide with a copper on alumina catalyst. Prior to operating the RWGS system the copper catalyst, which is produced from copper oxide reduction, must be conditioned to insure no oxygen is present in the system. Operating temperatures for processes on Mars are constrained and in general designs are not being considered which exceed 500 Celsius. At such temperatures, the RWGS reaction equilibrium is limited and does not favor the production of water. Thus in order to improve the overall conversion a separation step is required to allow the non reacted hydrogen and carbon dioxide to be recycled. This is achieved by passing the exit gases to a condenser to remove most of the water and then to a hollow fiber polymeric membrane, which preferentially permeates hydrogen and carbon dioxide. From the membrane, the reactants can be recycled while the byproduct carbon monoxide can be vented. The water produced is stored in a vessel and used as feed to an electrolysis unit, which produces oxygen as product and hydrogen, which can also be recycled to the reaction process. The RWGS process flow schematic with instrumentation labels is presented in Figure 1 below.

\section{RWGS OPERATION AND RESULTS}

The sensors and valves indicated in Figure 1 are referred to for this description of the RWGS operation The RWGS process is started up by energizing the heater HR2 and passing a small amount of hydrogen (typically $0.1 \mathrm{slpm}$ ), through the system from flow controller FC1 or FC2. 


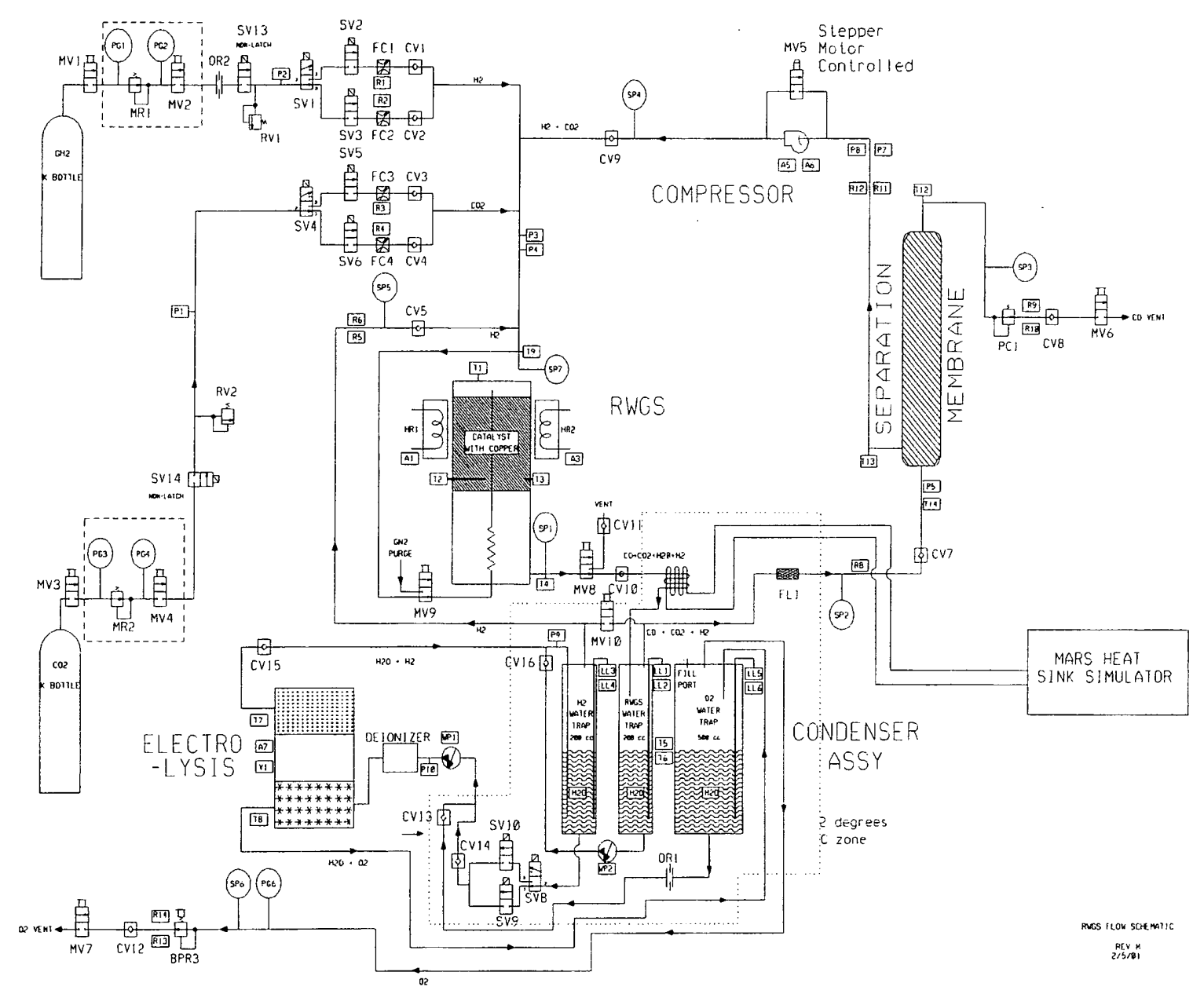

Figure 1 RWGS Process Flow Schematic

(Solenoid valves SV2 \& SV3) The hydrogen exiting the system is monitored using R9 \& R10 through the $\mathrm{CO}$ vent as the system pressure is regulated between 30 and 60 psia with pressure controller PC1. During the start up the recycle compressor is started and the pressure and flow are monitored through P8 and R12 respectively. (Measurements P7 and R11 are not working)

It takes approximately $1 \frac{1 / 2}{2}$ hours to heat and stabilize the reactor catalytic bed to $375-380$ Centigrade based on temperature probe $\mathrm{T} 2$. A proportional only temperature controller is used to aid in achieving this temperature, however it uses $\mathrm{T} 3$ as the control variable, which typically operates about 35 to 40 degrees cooler that $\mathrm{T} 2$ as shown in Figure 2 below. This indirect method of controlling the reactor temperature hinders the operation and the time to reach a desired steady state due to the manual intervention required. 


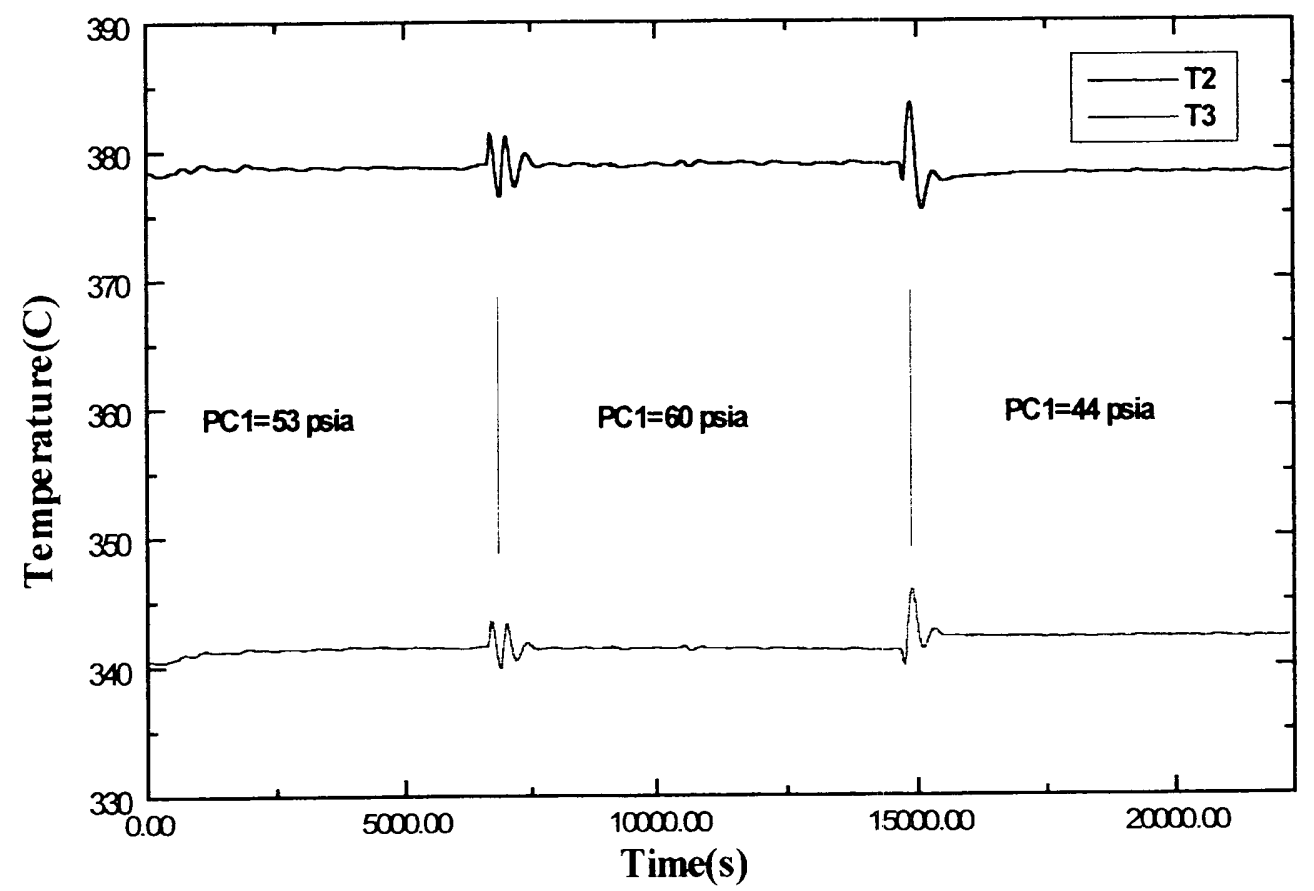

Figure 2 RWGS Reactor Temperatures during July $19^{\text {th }}$ Operation

Once temperature $\mathrm{T} 2$ exceeds 300 Centigrade, the carbon dioxide flow can be introduced through flow controller FC3 or FC4. It was found that waiting until the reaction temperature is closer to the desired temperature reduces the start up time since less gas is being heated and the endothermic reaction is not started. At this point the water electrolysis can be started if desired assuming sufficient water of low conductivity is available in the system. The water is pumped to the electrolysis unit using WP1 after passing through an ion exchange bed to purify the water. This is a problem area as the exchange resin appears to become saturated after $(\sim 15$ hours of operation) and requires new or regenerated resin.

Another problem with the use of electrolysis in conjunction with the RWGS process is related to the control of the system. The largest disturbance is introduced through the water level control system. When the electrolysis unit is running, the hydrogen water trap LL1 is continuously receiving a water input thus requiring periodic removal. The water is removed by opening solenoid valve SV10 whenever the level approaches full. When the valve opens the RWGS sees a sudden drop in pressure, which in turn disturbs the flows and temperatures in the system A similar disturbance occurs when the RWGS water receiver LL3 is drained after significant water production. Another potential problem with electrolysis is the difficulty in maintaining a constant source of hydrogen production, since the efficiency of the process is dependent on other process variables such as temperature, which are not automatically controlled.

The RWGS system was operated successfully on 7 different occasions each using a steady state 
reactor temperature near 379 Celsius. The electrolysis unit was operated the first 3 occasions where recycled hydrogen and oxygen were produced. Due to the disturbances discussed above however, a sufficient steady state operation could not be achieved and the experimental runs were for the next 4 occasions focused on RWGS only with no electrolysis. The $4^{\text {th }}$ run was successful in achieving steady state, however problems with the composition analysis limited the usefulness of the data. The best data was obtained during the runs of July 18,19 and $27^{\text {th }}$.

Table 1 presents a summary of average operating conditions for the runs of July 18,19 and $27^{\text {th }}$. It was found from the runs that the overall conversion based on hydrogen, increased with system pressure and consequently increased membrane pressure drop. The conversion also increased with lower feed rates to the system. It can also be observed from Table 1 that the ratio of product flow $\mathrm{R} 9$ to $\mathrm{H}_{2}$ feed decreases as conversion increases since one mole should leave the system for every 2 moles of reacted feed assuming all of the water is removed at the condenser.

Steady state operation was closely approached for each of the runs outlined in Table 1 in terms of reactor temperature as previously shown in Figure 2 and product flow as shown by Figure 3. It can be observed from Figure 4 however, that longer operating times are needed before the recycle and membrane feed reach steady state at the higher system pressures.

Table 1 RWGS July 18, 19 \& 27 Operating Summary

\begin{tabular}{|c|c|c|c|c|c|c|c|c|c|}
\hline Experimental & Feed & mem & P5 & P8 & Overall & R9/H2 Feed & T2 & T3 & T5 \\
\hline Run & Flow & $\Delta \mathrm{P}$ & Port 2 & Port 4 & Conversion & Ratio & & & \\
\hline $7 / 18 / 019: 30-10: 55$ & 2.0 & 35.94 & 52.65 & 16.71 & 97.37 & 1.0146 & 379.06 & 342.11 & 5.67 \\
\hline $7 / 18 / 011: 15-3: 45$ & 2.0 & 36.71 & 52.60 & 15.90 & 98.66 & 1.0175 & 378.80 & 344.10 & 5.61 \\
\hline $7 / 18 / 014: 00-5: 25$ & 2.4 & 34.68 & 52.76 & 18.08 & 95.04 & 1.0828 & 379.82 & 342.81 & 5.62 \\
\hline $7 / 19 / 011: 15-12: 00$ & 2.6 & 39.42 & 59.69 & 20.27 & 79.46 & 1.1508 & 378.97 & 341.42 & 5.88 \\
\hline $7 / 19 / 0112: 30-1: 55$ & 2.6 & 39.42 & 59.69 & 20.27 & 93.09 & 1.0570 & 378.97 & 341.42 & 5.88 \\
\hline $7 / 19 / 012: 15-4: 20$ & 2.6 & 27.11 & 44.08 & 16.97 & 94.62 & 1.2870 & 378.19 & 342.23 & 5.75 \\
\hline $7 / 27 / 0112: 30-1: 35$ & 2.20 & 34.73 & 52.63 & 17.90 & 96.37 & 1.0559 & 378.77 & 344.15 & 5.46 \\
\hline $7 / 27 / 013: 20-5: 05$ & 2.20 & 42.06 & 59.40 & 17.34 & 99.34 & 1.0079 & 378.18 & 344.92 & 5.83 \\
\hline
\end{tabular}

Table 2 provides a summary of mass balance results obtained from July $18^{\text {th }}$. A similar table was generated for the other 2 days however could not be included due to space restrictions. An overall mass balance error between 2 and $7 \%$ was observed over the 3 days of operation. After compensating for this error by adding the difference to the flow into the membrane, a component mass balance was performed and the resulting error are also presented in the tables. The analysis was performed using a gas chromatograph with a thermal conductivity detector for the $\mathrm{CO}$ and $\mathrm{CO}_{2}$ and a helium ionization detector for the $\mathrm{H}_{2}$. 
Table 2 July $18^{\text {th }}$ RWGS Mass Balance Summary

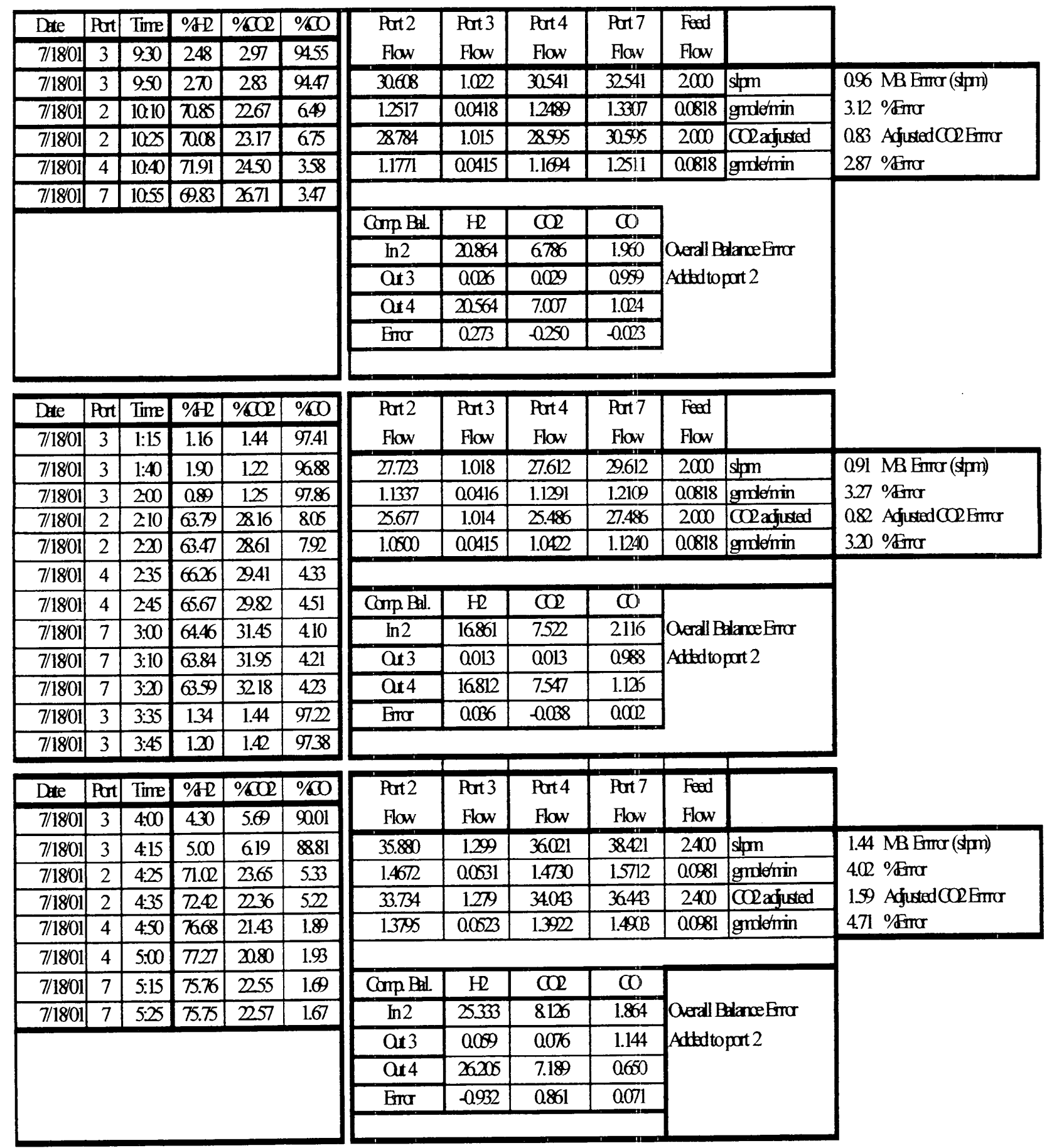




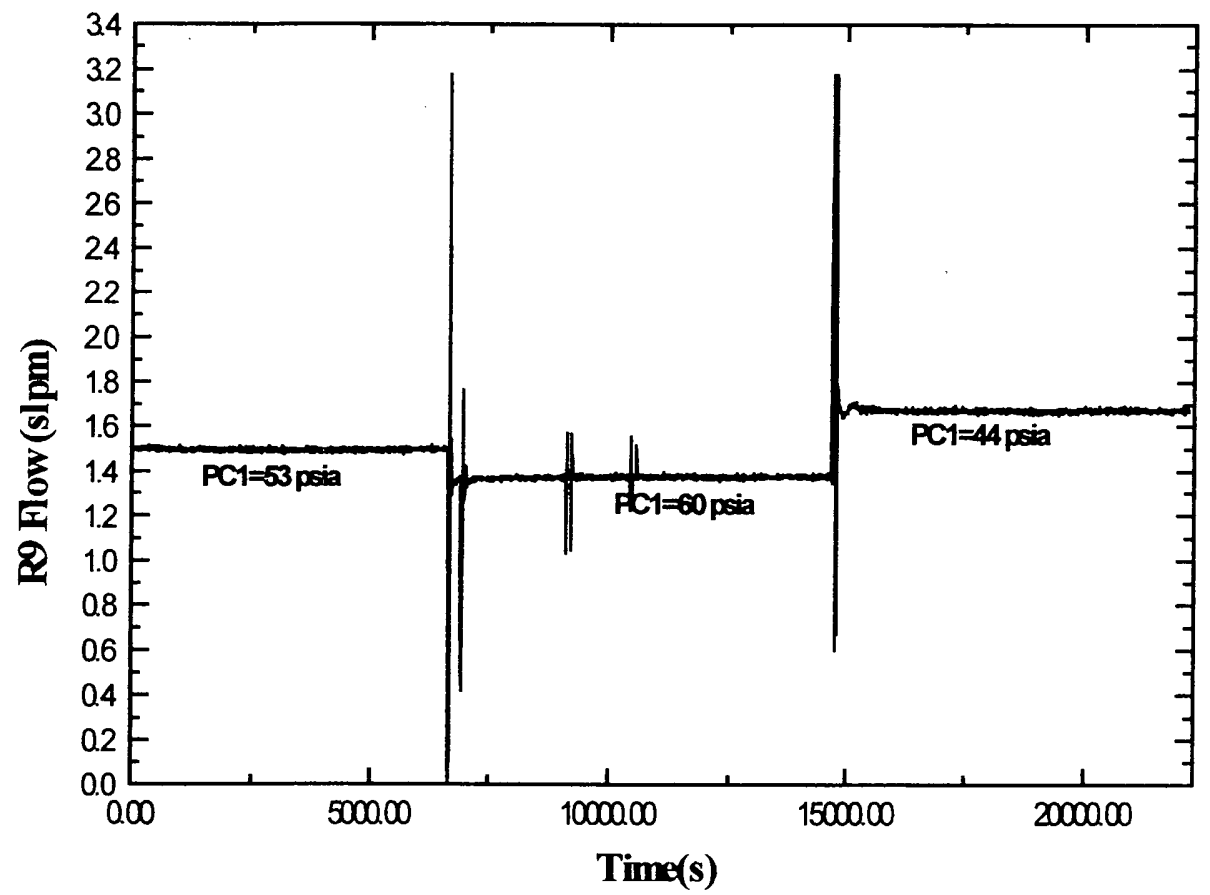

Figure 3 Product Flow R9 (CO Vent) for July $19^{\text {th }}$ Operation

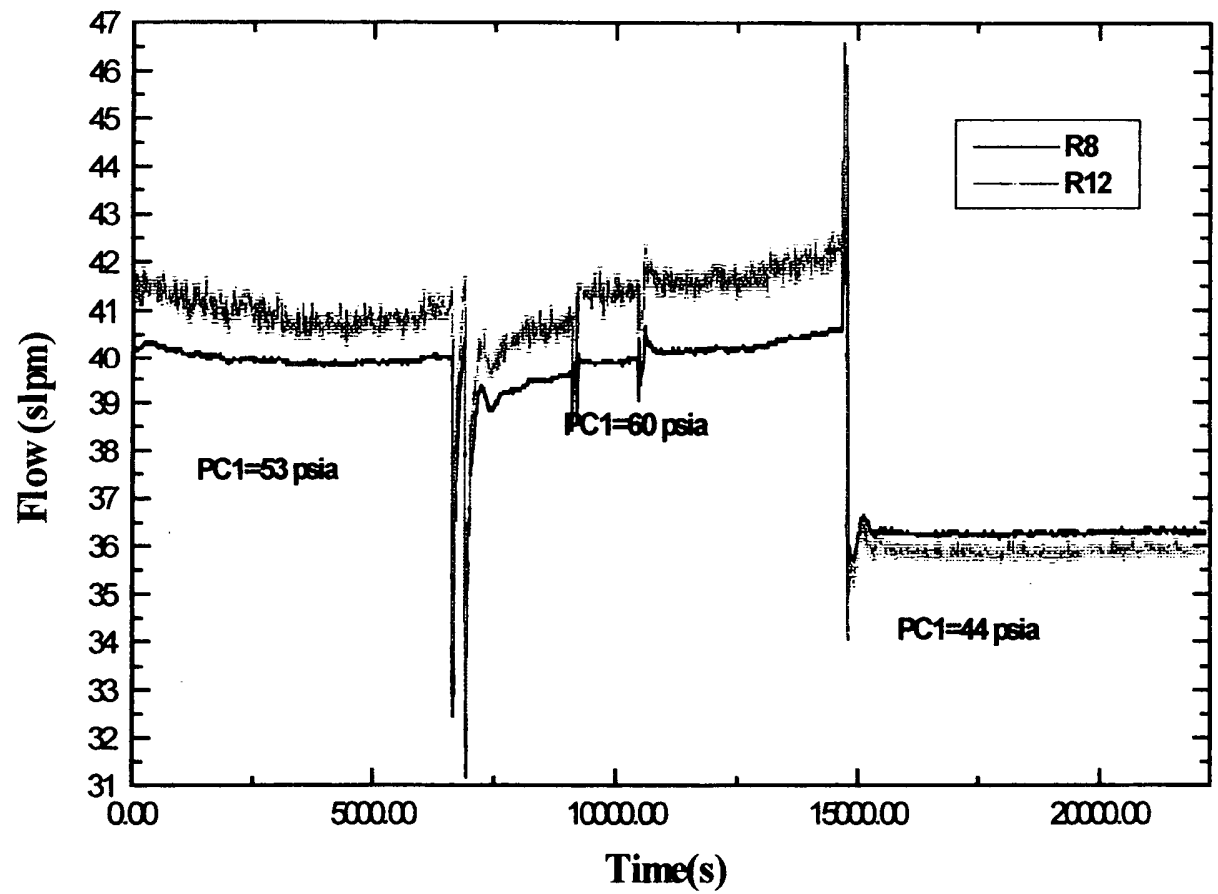

Figure 4 Recycle Flow R12 and Membrane Feed Flow R8 for July $19^{\text {th }}$ Operation 


\section{RWGS Model Description}

A brief description of the equations used to model the RWGS system is provided in this section. The RWGS material balance solution was implemented by programming in MATLAB code. A more detailed description of the modeling equations and associated theory can be found in the 1999 NASA/ASEE Summer Faculty Program Research Report ${ }^{[3]}$. The chemical equilibrium constant $\mathrm{K}$ for this reaction is given as a function of temperature by the expression: ${ }^{[4]}$ Fro products and reactants and in terms of conversion of a limiting reactant by the expression:

$$
\begin{gathered}
K=e^{13.148 \frac{5639.5}{T} 1.077 \ln T 5.44 \times 10^{4} T+1.125 \times 10^{7} T^{2}+\frac{49170}{T^{2}}} \\
K=\frac{[\mathrm{CO}]\left[\mathrm{H}_{2} \mathrm{O}\right]}{\left[\mathrm{CO}_{2}\right]\left[\mathrm{H}_{2}\right]}=\frac{\left(\Theta_{\mathrm{CO}}+x_{e q}\right)\left(\Theta_{\mathrm{H}_{2} \mathrm{O}}+x_{e q}\right)}{\left(\Theta_{\mathrm{CO}_{2}}-x_{e q}\right)\left(1-x_{e q}\right)}
\end{gathered}
$$

The values of $\Theta_{\mathrm{CO}}, \Theta_{\mathrm{H} 2 \mathrm{O}}, \Theta_{\mathrm{CO} 2}$ represent the molar ratios of those components to the limiting reactant (assumed to be hydrogen) in the inlet stream to the reactor. The limiting reactant is based $\mathrm{m}$ thermodynamic considerations, the value of $\mathrm{K}$ can is related to the concentrations of the on the total feed to the reactor, (recycle stream + fresh feed) instead of the fresh feed to the reactor. If carbon dioxide were the limiting reactant, equation 2 would need to be modified to reflect this. Given a reaction temperature, the value of $\mathrm{K}$ can be determined from equation 1 and the equilibrium conversion determined by solving equation 2 , which is a quadratic in $\mathrm{x}_{\text {eq }}$. The equilibrium conversion is the maximum conversion, which can be achieved, in a single pass through the reactor.

The exit gases from the reactor are sent to a condenser where most of the water is removed. For modeling purposes, the compositions of the liquid and vapor streams leaving the condenser are determined by employing Raoult's Law to determine the amount of water in the vapor phase and Henry's Law to determine the solubility and hence concentration of the gasses dissolved in the condensed phase.

The gases leaving the condenser are fed into a hollow fiber polymeric membrane which separates the components of a gas mixture based on a given components permeability to the polymer. The membrane operates in a countercurrent fashion, and is modeled based on a 1998 publication, ${ }^{[4]}$ which depicts the membrane as an $\mathrm{N}$ stage process as shown in Figure 5. Here, $\mathrm{L}_{\mathrm{k}, \mathrm{k}}$ and $\mathrm{x}_{\mathrm{j}, \mathrm{k}}$ are the total molar flow and mole fraction of component $\mathrm{j}$ in the feed/reject leaving stage $\mathrm{k}$, while $\mathrm{V}_{\mathrm{,k}}$ and $\mathrm{y}_{\mathrm{j}, \mathrm{k}}$ are the total molar flow and mole fraction of $\mathrm{j}$ in the permeate leaving stage $\mathrm{k}$. For each stage the mass transferred of a component $j$ on a given stage $m_{j, k}$ is given by the permeability coefficient of that component times the difference in partial pressures in component $j$ across the membrane. For $\mathrm{N}$ stages, a system of $\mathrm{N}$ nonlinear simultaneous equations is yielded for each component $\mathrm{j}$ requiring an iterative solution. 


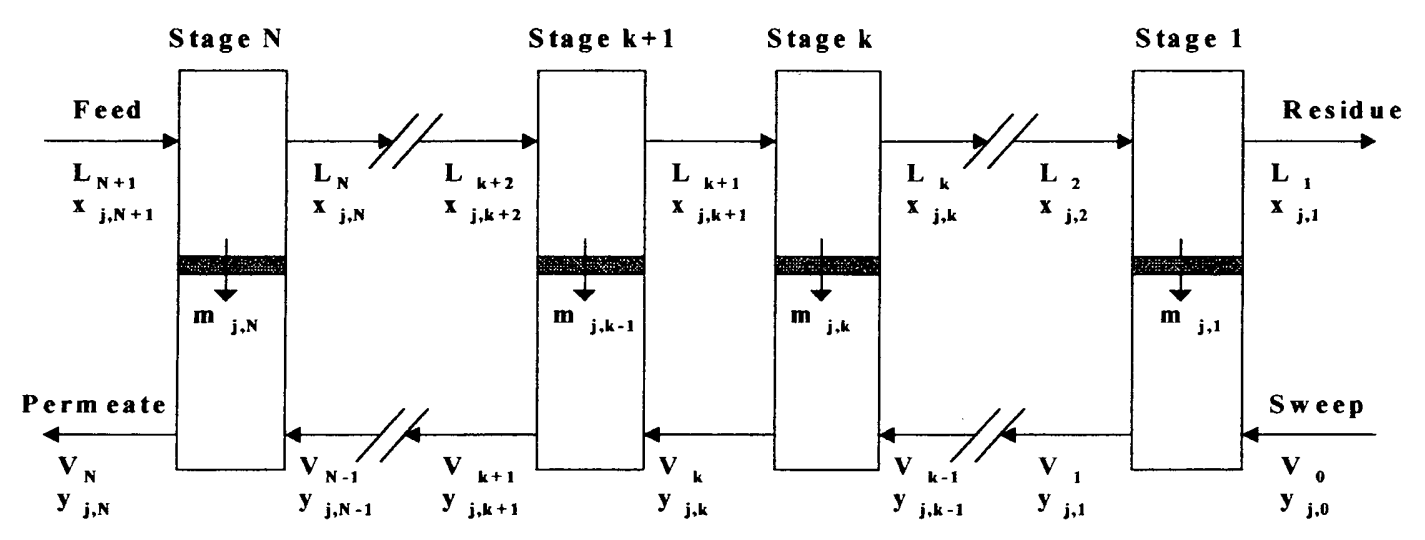

Figure 5 Flow Diagram for an N Stage Counter-Current Membrane

After the membrane equations have been solved, the permeate component molar flow rates are compared to those assumed initially in the recycle stream and adjusted using the Wegstein algorithm until overall convergence is achieved. Due to time constraints, only the model of the membrane was evaluated for validity. The errors in the component mass balances resulting from the operating data were corrected prior to input into the membrane model. This was done by adding or subtracting the required difference needed for mass balance closure to the component entering the membrane. The permeability coefficients in the membrane model for each component (excluding water) were refined based on a set of operating data on July $18^{\text {th }}$ such that the prediction error was zero for the set. The table presented below, shows the model prediction for permeate and reject for all the operating runs of July 18,19 and $27^{\text {th. }}$. While it can be observed that the model predicts well especially in face of the errors in the mass balance, it could be further refined with additional data.

\section{CONCLUSIONS}

Successful operation of the RWGS system was achieved during July 2001 confirming RWGS as a potential technology for water production on Mars. Various operational and analysis problems have been identified to aid in further system development. The model developed in Matlab for the RWGS system was validated for the membrane and found to have good predictive capabilities. Further testing of the system is needed to better develop the understanding of the RWGS process including the examination of the influence of the reactor temperature and the hydrogen to carbon dioxide feed ratios.

\section{ACKNOWLEDGMENTS}

I would like to express my sincere gratitude to Bill Larson \& Clyde Parrish for their effort, which has given me the opportunity to be involved in the development of knowledge to aid in the exploration of Mars. I would also like to thank Jan Surma and Curtis Ihlefeld for their technical assistance on this project. 
Table 3 Comparison of Experimental Values and Model Predictions for July 18, 19 \& 27

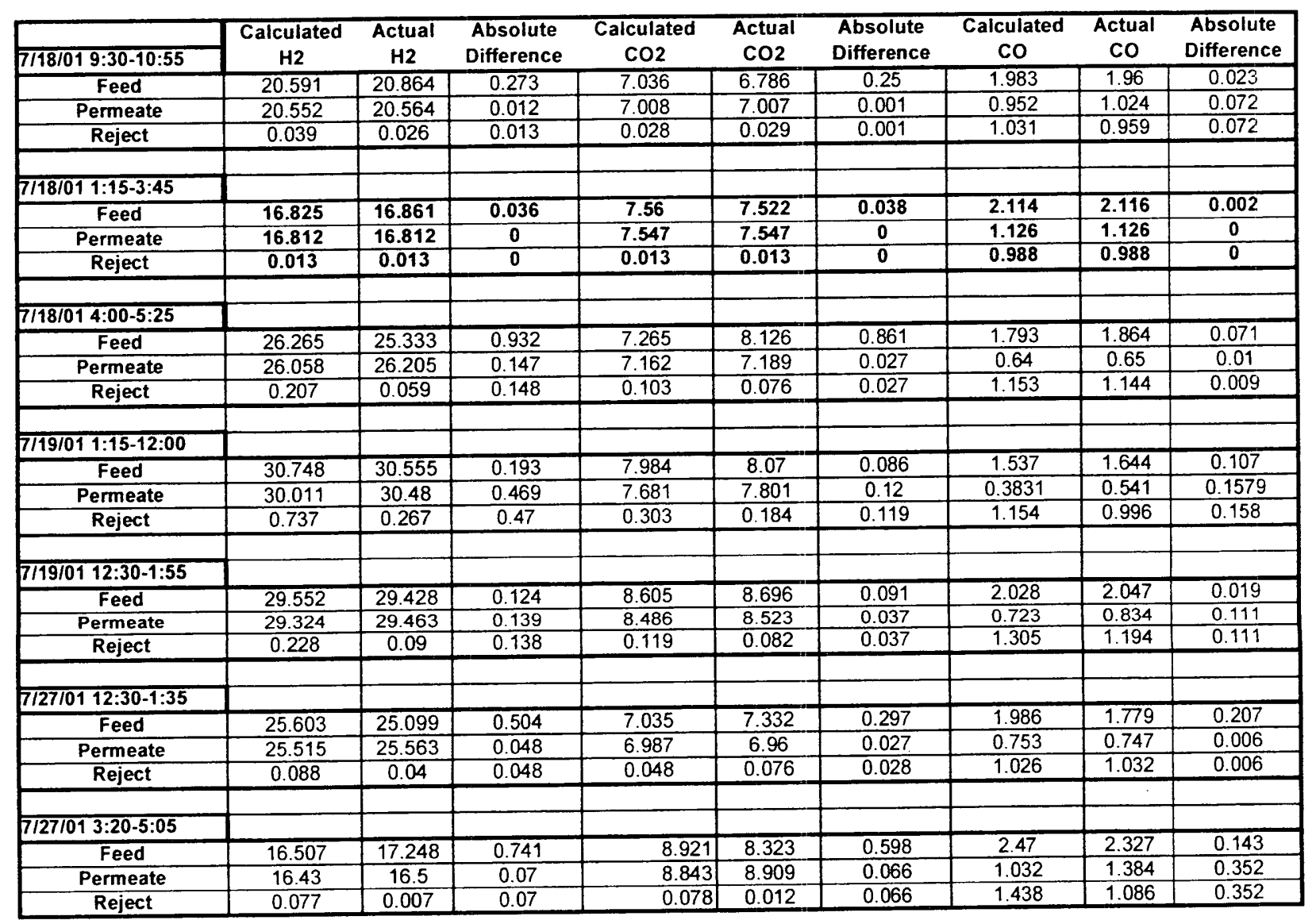

\section{REFERENCES}

[1] Zubrin R., Kito, T. and B. Frankie, "Report on the Construction of a Mars Methanol InSitu Propellant Production Unit", NASA Contract NAS9-97082, Sept., 1997.

[2] Frankie, B. and R. Zubrin, "Mars Reverse Water Gas Shift Unit Design Manual", Delivered to Dynacs Engineering and The Embedded Technology Development Group, June 30, 1999.

[3] Whitlow, J.E., "Modeling and Analysis of the Reverse Water Gas Shift Process for In-Situ Propellant Production", NASA/ASEE Summer Faculty Program Research Report, NASA CR-1999-208586, 1999.

[4] Bissett, L. "Equilibrium Constants for Shift Reactions", Chemical Engineering, October 24, 1977.

[5] Coker, D.T. , Freeman, B.D. and G.K. Fleming, "Modeling Multicomponent Gas Separation Using Hollow-Fiber Membrane Contactors, AICHE Journal, V. 44 , N 6, June 1998. 